\title{
PERENCANAAN PENGUATAN PRAKTEK KERJA LAPANGAN DALAM MENINGKATKAN KETERAMPILAN TEKNIS SISWA SMK PRODI DESAIN PEMODELAN DAN INFORMASI BANGUNAN (DPIB) UNTUK MENGHADAPI DUNIA KERJA
} (Studi Kasus di SMKN 9 Garut Jawa Barat)

\author{
Hermawan, $\mathrm{T}^{1}$, Wasliman ${ }^{2}, \mathrm{I}, \operatorname{Hanafiah}^{3}$, Muliani, $^{4}$ \\ Universitas Islam Nusantara \\ totokuninus@gmail.com
}

\begin{abstract}
ABSTRAK
Penelitian ini dilatar belakangi oleh lulusan SMK tidak sesuai kompetensinya dengan yang diharapkan oleh dunia kerja. Oleh sebab itu, perlu adanya manajemen penguatan praktek kerja lapangan dalam meningkatkan keterampilan siswa SMK kompetensi keahlian Desain Pemodelan dan Informasi Bangunan Desain Pemodelan dan Informasi Bangunan (DPIB) untuk menghadapi Dunia Kerja (Studi Kasus di SMKN 9 Garut). Tujuan penelitian ini adalah untuk memperoleh gambaran dan menganalisis tentang Perencanaan Penguatan Praktek Kerja Lapangan Dalam Meningkatkan Keterampilan Teknis Siswa SMK Untuk Menghadapi Dunia Kerja pada kompetensi keahlian Desain Pemodelan dan Informasi Bangunan Desain Pemodelan dan Informasi Bangunan (DPIB) SMKN 9 Garut.

Penelitian ini menggunakan penelitian kualitatif dengan pendekatan deskriptif. Teknik pengumpulan data melalui observasi, wawancara dan studi dokumentasi. Teori dalam penelitian ini adalah teori Manajemen menurut Hasibuan, M (2017:10), Mangkunegara, A (2017:2), teori PKL dalam Pedoman Praktik Kerja Lapangan (PKL) Peserta Didik SMK Direktorat Pembinaan SMK Kemendikbud (2018: 2) yakni:"Praktik Kerja Lapangan (PKL) adalah kegiatan pembelajaran yang dilakukan di DUDI dan/atau lapangan kerja lain untuk penerapan, pemantapan, dan peningkatan kompetensi.
\end{abstract}

Kata Kunci: Manajemen, PKL

\section{ABSTRACT}

The background of this research is that vocational school graduates do not match their competence with what is expected by the world of work. Therefore, there is a need for strengthening management of field work practices in improving the skills of Vocational School students in the competency of Design Modeling and Building Information Design Modeling and Building Information Design (DPIB) to face the world of work (Case Study at SMKN 9 Garut). The general purpose of this research is to obtain an overview and analysis of the Planning of Strengthening Field Work Practices in Improving Technical Skills of Vocational School Students for Facing the World of Work in the competency of Modeling Design and Building Information Design and Building Information Modeling Design (DPIB) competency in SMKN 9 Garut. This research uses qualitative research with a descriptive approach. Data collection techniques through observation, interviews and documentation study. The theory in this research is the theory of Management according to Hasibuan, M (2017: 10), Mangkunegara, A (2017: 2), the PKL theory in the Fieldwork Practice Guidelines (PKL) for Vocational School Students at the Ministry of Education and Culture's SMK Development Directorate (2018: 2), namely: "Field Work Practices (PKL) are learning activities carried out in DUDI and / or other work fields for the application, consolidation, and competency improvement. The implementation of PKL involves expert practitioners who are experienced in their fields to strengthen learning by guiding students during field work practices ". The results of this study are: 1. Planning to strengthen street vendors in improving technical skills of vocational students to face the world of work has been implemented simultaneously by all vocational managers and skill competencies, but on the other hand it is only done by hubin.

\footnotetext{
${ }^{1}$ Mahasiswa Pascasarjana Program S3 IImu Pendidikan UNINUS Bandung

2 Dosen Pascasarjana UNINUS Bandung

${ }^{3}$ Dosen Pascasarjana UNINUS Bandung

${ }^{4}$ Dosen Fak. Teknik UNINUS Bandung
} 
Keywords: Management, street vendor 


\section{PENDAHULUAN}

Pada kompetensi keahlian Desain Pemodelan dan Informasi Bangunan Desain Pemodelan dan Informasi Bangunan (DPIB) (DPIB) tujuan kurikulum mencakup empat aspek kompetensi, yaitu (1) aspek kompetensi sikap spiritual, (2) sikap sosial, (3) pengetahuan, dan (4) keterampilan. Aspek-aspek kompetensi tersebut dicapai melalui proses pembelajaran intrakurikuler, kokurikuler, dan ekstrakurikuler. DPIB adalah jurusan yang mempelajari tentang perencanaan bangunan, pelaksanaan pembuatan gedung, dan perbaikan gedung. Kegiatannya adalah belajar menggambar desain rumah, gedung, dan apartemen, menghitung biaya bangunan, melaksanakan pembangunan, serta memelihara konstruksi bangunan.

Selain pembelajaran di sekolah, sumber belajar bagi siswa SMK adalah Dunia Usaha/Dunia Industri (DU/DI). Sehingga SMK perlu kerjasama yang baik dengan DU/DI. DU/DI saat ini berkembang secara dinamis untuk itu SMK perlu menyiapkan lulusan yang professional dan terlatih terkait perkembangan teknologi.

Menurut Moss (1984:71) dalam : "Kerjasama antara sekolah dengan dunia usaha dan dunia industri merupakan suatu kesatuan usaha yang terus-menerus untuk mencapai tujuan bersama dengan membagi wewenang dan tanggung jawab". Kerjasama ini bukan karena hanya sekedar sebagai pendukung tetapi kerjasama dalam arti kemitraan yang sejajar (partnership). SMK perlu melakukan manajemen kemitraan dengan dunia usaha dan dunia industri sebagai salah satu bentuk pengelolaan manajemen yang saling terkait antara dua institusi dalam melaksanakan pendidikan dan pelatihan yang saling mengisi, saling membutuhkan, dan saling menguntungkan di dalam melakukan program kemitraan yang direncanakan.

SMK memiliki program pengenalan sejak dini pada DU/DI yaitu melalui Praktek Kerja Lapangan (PKL). Penyiapan siswa sebelum memasuki DU/DI harus dibekali dengan keterampilan sesuai dengan bidang keahlian. Hal ini tidak mungkin hanya dilakukan pihak SMK, karena meskipun pembelajaran praktik kejuruan yang diselenggarakan SMK ditunjang dengan peralatan yang lengkap dan modern, pada dasarnya hanya mampu menyajikan dasar-dasar keterampilan dalam situasi tiruan (simulasi). Oleh sebab itu, untuk mencapai tujuan pendidikan SMK perlu adanya kerjasama dan partisipasi dari DU/DI. Kerjasama yang dilakukan dengan pihak DU/DI untuk PKL siswa sangat dibutuhkan, karena kemajuan teknologinya lebih cepat berkembang daripada SMK dan dapat memberikan pengalaman baru bagi siswa dalam menyiapkan lulusan memasuki DU/DI.

Dalam sebuah penelitian yang dilakukan Darmono dkk tahun 2014 menyebutkan bahwa "Keberhasilan pendidikan vokasional tidak hanya diukur dari segi mutunya saja, melainkan juga dari segi relevansinya." Mutu lulusan dapat dianggap relevan apabila yang didapatkan lulusan lebih besar dari apa yang diharapkan. Hal ini selaras dengan pendapat Muftihatun (2017: 2):

"Peran DU/DI sangat penting ketika ikut menetapkan standar sebatas menerima kerjasama dari pihak sekolah tetapi perlu penerapan pembelajaran berbasis produksi agar menjadi manusia yang berkompeten kompetensi, merumuskan kurikulum bersama yang berbasis kompetensi, ikut dalam proses pembelajaran dengan memberikan kesempatan siswa PKL dan memberikan sertifikasi serta ikut dalam uji kompetensi sehingga lulusan pendidikan kejuruan merupakan tenaga yang siap pakai di DU/DI".

Dalam hal ini adanya keterlibatan DU/DI dalam pembelajaran SMK meski pelaksanaannya tidak disekolah dapat bermanfaat untuk kedua belah pihak, baik untuk DU/DI maupun pihak sekolah. Menurut Bennett (2006:1) bahwa: "Tantangan terbesar dunia pendidikan saat ini adalah menghasilkan lulusan yang mempunyai kemampuan akademik (academic skills) dan kemampuan pada penguasaan keterampilan (technical skill) yang seimbang".

Sesuai dengan hasil penelitian tersebut, maka penguasaan keterampilan (technical skill) berguna untuk mengetahui seberapa baik kemampuan akademik (academic skills) dan kemampuan pada penguasaan keterampilan (technical skill) yang dapat diolah oleh siswa saat pelaksanaan praktek kerja lapangan (PKL).

Dalam Depdiknas (2008) Penyusunan praPKL mengenai berbagai komponen yang terkait dengan PKL siswa merupakan tanggungjawab sekolah seperti waktu pelaksanaan, pembekalan peserta didik dan pembimbing. Waktu pelaksanaan PKL pihak sekolah sebagai pihak yang menentukan, tetapi penentuan waktu juga harus disepakati bersama antara pihaksekolah dengan DU/DI tempat praktik nantinya. Pihak sekolah yang harus berinisiatif dahulu untuk menjemput bola mencari waktu yang tepat untuk PKL dan kesepakatan waktu dimaksudkan agar tidak 
mengganggu proses produksi yang ada di DU/DI. Namun, pada faktanya, hal-hal tersebut tidak sesuai dengan apa yang diharapkan terlebih dalam menghasilkan lulusan siap kerja, karena para pengelola pendidikan SMK masih berorientasi pada pembenahan internal organisasi dan kurangnya sosialiasi dari pihak sekolah ke DU/DI sehingga PKL hanya dilakukan secara formalitas.

Berdasarkan penjajagan awal yang didapat berdasarkan wawancara dengan ketua Kompetensi Keahlian Teknologi Konstruksi dan Properti Kompetensi Keahlian Desain Pemodelan dan Informasi Bangunan Desain Pemodelan dan Informasi Bangunan (DPIB) SMKN 9 Garut bahwa kendala yang dihadapi kompetensi keahlian ini adalah sebagai berikut:

1) Input siswa pada kompetensi keahlian DPIB merupakan sisa dari kompetensi keahlian lain saat pendaftaran, oleh sebab itu semangat belajar pun berpengaruh pada siswa. Ada beberapa siswa yang tidak mampu dalam mengikuti pembelajaran seperti praktek menggambar sehingga mereka mengundurkan diri.

2) Pada proses PKL ada gap antara DU/DI, karena pihak sekolah kurang memiliki link ke DU/DI.

3) Kesepahaman antara kurikulum yang ada berbeda jauh dengan kebutuhan DU/DI.

4) Peralatan atau spesifikasi komputer yang ada di sekolah core I3 dan di DU/DI sudah core 7 berbeda jauh, sehingga siswa ketika PKL belajar beradaptasi lagi.

5) Keterbatasan komputer berbanding 1:2, sehingga 1 komputer dipakai oleh 2 orang siswa secara bergantian.

Berdasarkan fakta tersebut, maka penulis ingin mengetahui bagaimana perencanaan Ppenguatan PKL dalam meningkatkan keterampilan teknis siswa SMK untuk menghadapi dunia kerja, meliputi:

a) Tujuan PKL kompetensi keahlian Desain Pemodelan dan Informasi Bangunan Desain Pemodelan dan Informasi Bangunan (DPIB) dengan DU/DI.

b) Materi PKL kompetensi keahlian Desain Pemodelan dan Informasi Bangunan Desain Pemodelan dan Informasi Bangunan (DPIB) dengan DU/DI.

c) Metoda PKL kompetensi keahlian Desain Pemodelan dan Informasi Bangunan Desain Pemodelan dan Informasi Bangunan (DPIB) dengan DU/DI. d) Media PKL kompetensi keahlian Desain Pemodelan dan Informasi Bangunan Desain Pemodelan dan Informasi Bangunan (DPIB) dengan DU/DI.

e) Kriteria Ketuntasan Minimal (KKM) PKL kompetensi keahlian Desain Pemodelan dan Informasi Bangunan Desain Pemodelan dan Informasi Bangunan (DPIB) dengan DU/DI

f) Pemilihan DU/DI untuk PKL kompetensi keahlian Desain Pemodelan dan Informasi Bangunan Desain Pemodelan dan Informasi Bangunan (DPIB).

g) Penyusunan Program PKL

h) Pembekalan Peserta PKL

i) Penetapan Pembimbing PKL.

\section{METODE}

Penelitian ini menggunakan penelitian kualitatif dengan pendekatan deskriptif. Teknik pengumpulan data melalui observasi, wawancara dan studi dokumentasi.

\section{HASIL DAN PEMBAHASAN}

Berdasarkan hasil temuan dan interpretasi perencanaan penguatan PKL dalam meningkatkan keterampilan teknis siswa SMK Garut kompetensi keahlian Desain Pemodelan dan Informasi Bangunan (DPIB) adalah sebagai berikut:

a) Tujuan PKL Kompetensi keahlian Desain Pemodelan dan Informasi Bangunan (DPIB) dengan DU/DI.

Sebelum pelaksanaan PKL, dirumuskan terlebih dahulu tujuan PKL karena tujuan merupakan unsur dari rencana, sesuai dengan pendapat Hasibuan, M (2017:249), bahwa: "Rencana adalah sejumlah keputusan yang menjadi pedoman untuk mencapai suatu tujuan tertentu. Jadi setiap rencana mengadung dua unsur yaitu tujuan dan pedoman.

Tujuan PKL dalam meningkatkan keterampilan teknis siswa SMK Garut kompetensi keahlian Desain Pemodelan dan Informasi Bangunan (DPIB) hampir mendekati pada Pedoman Praktik Kerja Lapangan (PKL) Peserta Didik SMK Direktorat Pembinaan SMK Kemendikbud (2018: 5) terhadap upaya peningkatan kualitas pendidikan di SMK. Meskipun tidak mencakup semua hal yang ada pada pedoman tersebut yakni pada hal mengaktualisasikan salah satu bentuk aktivitas dalam penyelenggaraan Model Pendidikan Sistem Ganda (PSG) antara SMK dan Institusi Pasangan 
yang memadukan secara sistematis dan sistemik program pendidikan di sekolah (SMK) dan program pelatihan penguasaan keahlian di dunia kerja (DUDI) belum terwujud, karena adanya perbedaan antara materi dan media pembelajaran antara di sekolah dan di DU/DI.

Penyajian materi PKL Kompetensi Keahlian DPIB dari sekolah adalah berdasarkan berdasarkan pemilahan kompetensi berdasarkan analisis Kompetensi Dasar (KD) dan topik pembelajaran/pekerjaan dari mata pelajaran pada Kompetensi Keahlian. Hal ini sesuai dengan

Namun, dalam hal ini sekolah mengalami kesulitan dalam mencari institusi pasangan, sehingga ketika pengelola kompetensi keahlian DPIB menghubungi perusahaan-perusahaan yang mereka kenal, kemudian siswa melaksanakan PKL. Hasilnya siswa mendapatkan materi PKL sesuai dengan proyek pekerjaan yang diterima oleh DU/DI seperti pembuatan sketsa gambar, membantu pembuatan laporan pekerjaan yang didapat masing-masing DU/DI.

Oleh sebab itu, siswa mendapatkan materi PKL secara beragam, tergantung apa yang menjadi tugas masing-masing di DU/DI. Jika DU/DI yang dijadikan tempat PKL merupakan perusahaan yang banyak mendapatkan proyek tentunya keahlian siswa dan pengalamannya banyak, tetapi jika tidak maka materi yang didapatkan sangat minim.

Berdasarkan temuan tersebut, tentunya pihak sekolah harus lebih selektif lagi dalam mencari mitra DU/DI agar materi yang didaptkan siswa sesuai dengan tuntutan industri.

b) Metoda PKL Kompetensi keahlian Desain Pemodelan dan Informasi Bangunan (DPIB) dengan DU/DI.

Metoda pelaksanaan PKL rata-rata pada program 3 tahun, yaitu melaksanakan PKL selama 3 bulan pada semester 5. Pada awal tahun pengelola kompetensi keahlian DPIB sudah mencari DU/DI sebagai tempat untuk para siswa melaksanakan PKL bertujuan untuk meminta masukan dan saran ke industry dan menyediakan tempat bagi siswa DPIB untuk PKL.

Setelah itu, sinkronisasi kurikulum dengan cara meminta masukan dan saran terkait kompetensi yang perlu dimiliki siswa SMK agar sesuai dengan kebutuahn industri. Hal ini dilakukan agar siswa dalam menjalankan PKL sungguh-sungguh seolah mereka benar bekerja di industri, bukan hanya meyelesaikan kewajiban sekolah. Disisi lain, agar industri pun melirik kompetensi yang dimiliki siswa khususnya technical skil, sehingga saat mereka lulus pada semester 6 DU/DI merekrut, siswa sudah siap bekerja.

Kegiatan dengan mengadakan kunjungan ke industri-industri atau jemput bola meminta masukan dan saran keindustri merupakan tindakan yang efektif bagian kurikulum untuk mengsinkronkan kompetensi di sekolah dengan di industri sebagai wujud dari Pendidikan Sistem Ganda (PSG) yang merupakan implementasi link and match. Hal tersebut sesuai dengan pendapat Indra Djati Sidi, dkk.(2001: 45), bahwa pendidikan sistem ganda merupakan implementasi dari konsep link and match, yaitu perancangan kurikulum, proses pembelajaran, dan penyelenggaraan evaluasinya didesain dan dilaksanakan bersamasama oleh pihak sekolah dan industri.

c) Media PKL Kompetensi keahlian Desain Pemodelan dan Informasi Bangunan (DPIB) dengan DU/DI.

Pemanfaatan media PKL Kompetensi keahlian Desain Pemodelan dan Informasi Bangunan (DPIB) menggunkan media cetak yang disediakan oleh sekolah, sedangkan laptop pribadi ataupun media pembelajaran yang ada di industri, tentunya hal ini akan berpengaruh pada pengetahuan siswa dan skill nya, karena saat industri memiliki media pembelajaran dan alatalat yang canggih tentunya akan menambah pengetahuan dan skill siswa dalam menggunakannya.

Terlebih jika alat/ media pembelajaran yang ada di DU/DI sesuai dengan standar industri, bahkan jika DU/DI sedang mendapatkan proyek, siswa dapat secara langsung menggunakan media nyata/ real seperti mengontrol yang sedang mengerjakan pembangunan atap atau pondasi. Hal ini dapat menyiapkan siswa untuk mengetahui pekerjaan apa yang akan mereka hadapi saat lulus dari kompetensi keahlian DPIB. Namun, jika siswa praktik kerja lapangan di tempat yang biasa saja, hasilnya sama saja bahkan lebih baik di sekolah.

d) Kriteria Ketuntasan Minimal PKL Kompetensi keahlian Desain Pemodelan dan Informasi Bangunan (DPIB) dengan DU/DI.

Kriteria Ketuntasan Minimal (KKM) PKL berdasarkan Standar Peminatan dari Permendiknas no 75 dan nilai itu sudah menjadi wewenang dari industri, karena siswa PKL hanya 3 bulan, maka kolaborasi dengan sekolah yaitu $40 \%$ dari sekolah dan $60 \%$ dari DU/DI. KKM ini tentunya merupakan kriteria minimal yang harus diperoleh siswa sebagai syarat lulus, sehingga perlu adanya keseriusan menjalani PKL. Karena pada kesempatan PKL ini bukan hanya sekedar nilai yang didapatkan siswa, namun lebih dari itu adalah 
pengetahuan dan skill lainnya dari tempat PKL di DU/DI.

e) Pemilihan DU/DI untuk PKL Kompetensi keahlian Desain Pemodelan dan Informasi Bangunan (DPIB).

Pendataan DU/DI dilakukan oleh panitia khusus yang dibentuk oleh sekolah. Pendataan dimulai ketika PKL tahun sebelumnya dengan cara sekolah memberikan lembar kesediaan (bersedia/tidak bersedia) untuk DU/DI yang telah menjalin kerja sama untuk melanjutkan kerjasama lagi dengan menjadi tempat PKL lagi untuk siswa tahun depan.

Rekapan DU/DI tersebut dijadikan acuan siswa untuk mendatangi DU/DI tersebut dan menyampaikan surat permohonan. DU/DI yang sudah bersedia bisa juga menolak siswa dengan alasan kouta dan lain sebagainya sehingga DU/DI yang sudah di data bisa berubah sewaktu-waktu menyesuaikan keadaan siswa. Siswa dapat mengajukan DU/DI yang belum ada di daftar yang penting DU/DI tersebut mengijinkan siswa untuk PKL di DU/DI tersebut.

Hal diatas sesuai dengan pendapat Wahyu Nurharjadmo (Eling Damayanti, 2014: 46), bahwa pemetaan Prakerin atau tempat Prakerin yaitu kegiatan yang dilakukan untuk memperoleh kejelasan tentang berbagai hal, yaitu tentang kejelasan pihak yang terlibat serta jadwal kegiatan Prakerin. Sedangkan menurut Isnu (2012: 50), pemetaan Dunia kerja sangat penting dilakukan sebelum program Prakerin dirancang. Hal ini dimaksudkan agar dunia kerja yang dijadikan mitra benar-benar sesuai dengan program keahlian yang sedang ditekuni oleh peserta didik, sehingga tujuan Prakerin tercapai dengan baik.

Pemilihan DU/DI tentunya harus sesuai dengan buku pedoman PKL dari Kemendikbud yaitu bidang pekerjaan DU/DI sesuai dengan paket keahlian, memiliki order pekerjaan yang rutin dan memadai secara ekonomis, mempunyai latar belakang manajemen yang baik dan tertib, lokasi DU/DI berada disekitar tempat tinggal siswa, ataudi luar daerah. Berdasarkan hasil temuan DU/DI untuk PKL DPIB SMK Garut, rata-rata berada di luar daerah Garut karena DU/DI yang ada sedikit dan tidak memungkinkan untuk siswa PKL, sehingga pengelola SMK memilih DU/DI di daerah Bandung, Bekasi dan sekitarnya.

Biasanya pemilihan berdasarkan DU/DI yang dikenal oleh para guru di program DPIB dan memenuhi syarat untuk tempat PKL siswa memudahkan dalam komunikasi, bahkan untuk tahun selanjutnya siswa kompetensi keahlian DPIB dipersilahkan untuk PKL di DU/DI mitra. Hal ini tentunya tidak lepas dari peran serta guru DPIB yang memiliki jaringan yang banyak di luar daerah Garut, sehingga saat siswanya akan melaksanakan PKL, dengan sigap para guru sudah memiliki list, DU/DI mana saja yang bisa dihubungi.

Setelah itu guru membuat surat permohonan perijinan PKL untuk diajukan ke sekolah dan dibuatkan surat ijin resmi dari sekolah.

Hal tersebut sesuai dengan Kemdikbud (2015: 3) pemetaan industri bertujuan untuk memperoleh Institusi Pasangan (DU/111 ISSN: 1907-4034 Manajemen Praktik Kerja...(Diyah Setiyaningrum) DI) yang sesuai dengan KD yang sedang ditekuni oleh peserta didik, serta meningkatkan jalinan hubungan kerja sama antara sekolah dengan dunia kerja. Jadi, pemetaan DU/ DI dapat untuk mengetahui industri-industri mana yang masih bisa dipakai untuk PKL yang sesuai dengan kompetensi siswa, dan yang memiliki pertumbuhan bagus di masyarakat, dengan harapan dapat bekerjasama dengan baik.

f) Penyusunan Program PKL

Penyusuan program PKL dilakukan secara bersama oleh pengelola kompetensis keahlian DPIB SMKN 9 Garut mulai dari perencanaan sampai evaluasi, sehingga aktivitas PKL terasa adanya koordinasi antar pengelola baik pihak hubin, kesiswaan dan kompetensi keahlian, Pembekalan Peserta PKL

Sebelum pembekalan PKL, persiapan yang adalah pengadaan buku panduan praktek kerja lapangan, buku jurnal kegiatan siswa dan daftar hadir sehingga saat pembekalan siswa sudah memilikinya serta mempersiapkan surat tugas untuk guru pembimbing yang akan mengantarkan siswa ke dunia usaha/dunia industri. Kegiatan ini disiapkan oleh panitia PKL baik oleh hubin ataupun pengelola kompetensi keahlian.

Pembekalan PKL dilaksanakan terhadap siswa secara menyeluruh ataupun per jurusan. Hal ini dilakukan untuk mempersiapkan siswa siswa secara mental untuk memberikan sosialisasi kepada siswa mengenai pelaksanaan praktek kerja lapangan. Pembekalan dilakukan tiga hari sebelum keberangkatan yaitu hari. Pematerinya adalah dari UPTD, wakil kepala sekolah bagian hubin dan kepala porgram.

Siswa dibekali informasi mengenai dunia usaha/dunia industri secara umum dan bagaimana menempatkan diri di dunia usaha/dunia industri yang merupakan lingkungan kerja baru bagi siswa. Termasuk didalamnya pencatatan setiap aktivitas kedalam buku agenda praktek kerja lapangan, kompetensi/sup kompetensi yang diharapkan dilaksanakan selama praktek kerja lapangan, 
penilaian, pembuatan laporan, sertifikasi praktik kerja industri (praktek kerja lapangan), etika, sopan santun dan cara berpakaian (berpenampilan). Pembekalan diberikan sesuai program keahlian. Pemateri dari sekolah adalah Ketua Program keahlian masing-masing dan ditambahkan dari DU/DI mitra.

Pembekalan diadakan kepada para siswa dan guru pembimbing PKL baik secara menyeluruh ataupun di tingkat kompetensi keahlian sekaligus pembagian atribut dan dokumen PKL, kemudian Upacara Pelepasan Pembekalan berisi sosialisasi kepada siswa berupa hal-hal yang berkaitan dengan PKL antara lain: kewajiban bagi siswa, larangan bagi siswa, sanksi-sanksi dan petunjuk bagi pembimbing sekolah dan pembimbing di DU/DI.

Setelah pembekalan di sekolah, selanjutnya pengantaran siswa ke DU/DI dilakukan oleh guru pembimbing dengan membawa surat tugas dari sekolah. Guru pembimbing menyampaikan kepada DU/DI kemampuan awal siswa dan apa saja yang harus siswa pelajari di DU/DI lebih bagus lagi jika DU/DI dapat memberikan pengetahuan lebih yang belum dipelajari siswa di sekolah.

g) Penetapan Pembimbing PKL

Pembimbing PKL terdiri atas pembimbing sekolah dan pembimbing industri. Di SMKN 9 Garut, guru yang menjadi pembimbing adalah guru yang menyanggupi menjadi guru pembimbing PKL dan telah memasukkan agenda PKL kedalam agenda tahunannya untuk syarat administrasi guru. Guru pembimbing PKL minimal mengetahui kemampuan siswanya dibidang keahlian, ketika menyerahkan ke DU/DI pun guru pembimbing tahu apa saja yang harus dipelajari siswa selama PKL disana sehingga DU/DI mengetahui tujuan siswa PKL disana untuk mempelajari apa.

Selain guru pembimbing PKL sekolah, siswa juga mendapat pembimbing dari DU/DI untuk memfokuskan pada bidang atau aspek yang ingin dicapai berdasarkan komunikasi dari pembimbing sekolah., karena pekerjaan di DU/DI bermacam-macam dan kompleks sehingga dari sekolah perlu lebih mengerucutkan lagi tujuan siswa PKL untuk mencapai kompetensi apa saja disetiap program keahlian.

\section{PENUTUP}

Perencanaan penguatan PKL dalam meningkatkan keterampilan teknis siswa SMK untuk menghadapi dunia kerja sudah dilaksanakan, secara bersamaan oleh seluruh pengelola SMK dan kompetensi keahlian

\section{E. DAFTAR PUSTAKA}

Fernando, Z.A., Inra, A., dan Yustisia, H. (2015). Kesiapan Mahasiswa Program Studi Teknik Sipil dan Bangunan di Bidang Teknik Sipil. CIVED ISSN 2302-3341. 3(1): 5842590

Hamalik, Oemar. (2007). Manajemen Pelatihan Ketenagakerjaan Pendekatan Terpadu. Jakarta: Bumi Aksara.

Hasibuan, M (2017). Manajemen Sumber Daya Manusia (Cet-17) Jakarta: PT Bumi Aksara.

Hersey, P. \& K. Blanchard. (1992). Manajemen Perilaku Organisasi (terjemahan oleh Agus Dharma). Erlangga.

Kadarisman, M. 2012. Manajemen Kompensasi. Jakarta: Rajawali pers.

Mangkunegara, A.A. (2017). Manajemen Sumberdaya Manusia Perusahaan. (Cet14).Bandung: PT. Remaja Rosdakarya.

Moleong, J.L (2019). Metodologi Penelitian (cet39). Bandung: Rosdakarya.

Muftihatun (2017). Pola Praktik Kerja Lapangan (PKL) Program Keahlian Teknik Gambar Bangunan SMK Negeri 1 Seyegan. Jurnal Pendidikan Teknik Sipil dan Perencanaan .

Ranupandojo, H., dan Suad Husnan, (1990). Manajemen Personalia, Edisi III, Yogyakarta: BPFE. 